\title{
Fracture toughness of adherends bonded with two-part acrylic-based adhesive: double cantilever beam tests under static loading
}

\author{
Hyun-Bum Kim", Kimiyoshi Naito and Hiroyuki Oguma
}

${ }^{*}$ Correspondence:

KIM.Hyunbum@nims.go.jp

National Institute

for Materials Science,

Research Center for Structural

Materials (RCSM), Polymer

Matrix Hybrid Composite

Materials Group, 1-2-1

Sengen, Tsukuba, Ibaraki

305-0047, Japan

\begin{abstract}
Adhesives are used in various industries to bond materials. The failure criteria of adhesive joints are based on the strength (peel) and fracture mechanisms of the materials. It is important to investigate these criteria in relation to the propagation and separation of Mode I, II, and III cracks. The purpose of this study is to use double cantilever beam (DCB) tests to measure fracture toughness in aluminum alloy (5052-H34), glass fiberreinforced polypropylene matrix composite, and carbon fiber-reinforced epoxy matrix composite adherends bonded with a two-part acrylic-based adhesive. The fracture behaviors of the specimens are also discussed. DCB tests are carried out to measure fracture toughness under Mode I loading of adhesively bonded joints with different types of adherends. The fracture toughnesses of the aluminum alloy, glass-fiberreinforced polypropylene matrix composite (GF/PP), and carbon fiber-reinforced epoxy matrix composite (CF/EP) specimens are 1071, 1438, and $1652 \mathrm{Jm}^{-2}$, respectively. The fracture surfaces of the aluminum alloy, GF/PP, and CF/EP specimens are observed to be of the interfacial, adherend, and cohesive types, respectively.
\end{abstract}

Keywords: Double cantilever beam, Composites, Acrylic-based adhesive, Fracture toughness, Bonding

\section{Background}

Adhesives are used in various industries to bond materials. The drawbacks of using adhesives include relatively low resistance to high temperatures and problems with quality assurance [1]. However, the advantages include a continuous bond, lower process temperatures, and the ability to join several components together in a single operation [2].

Adhesively bonded lap joints are commonly studied to measure the shear strength of adhesive joints [3-5]. These joints produce tensile stresses (peel) and shear at their ends [6]. The failure criteria of adhesive joints are based on the strength (peel) and fracture mechanisms of the materials [7]. It is important to investigate these criteria in relation to the propagation and separation of Mode I, II, and III cracks. In terms of the fracture mechanisms, double cantilever beam (DCB) tests are commonly used in Mode I to measure the fracture toughness of adhesive joints $[8,9]$. The advantages of using this test

(c) 2016 The Author(s). This article is distributed under the terms of the Creative Commons Attribution 4.0 International License (http://creativecommons.org/licenses/by/4.0/), which permits unrestricted use, distribution, and reproduction in any medium, provided you give appropriate credit to the original author(s) and the source, provide a link to the Creative Commons license, and indicate if changes were made. 
include its relatively simple method and the facility to measure the fracture toughness by using beam theory $[10,11]$. DCB tests of steel and fiber-reinforced plastic (FRP) adherends bonded with adhesives (e.g., polyurethane, epoxy, silicone, phenol-formaldehyde, and methacrylate) have been conducted to measure fracture toughness [12-15].

A few detailed reports have been made about the fracture behavior of adherends bonded with acrylic-based adhesive under Mode I loading [16-18]. These describe the effects of surface treatments on Mode I fracture energy using FRP and aluminum alloy adherends bonded with a toughened acrylic adhesive. The results show that fracture toughness is enhanced by applying surface treatments such as grit blast and $\gamma$-methac ryloxypropyltrimethoxysilane ( $\gamma$-MPS). Adherends also need to be considered not only to determine the designs of structures but also to deal with various materials such as metal/metal, thermoset, and thermoplastic matrices.

The purpose of this study is to measure fracture toughness by means of DCB tests on aluminum alloy, glass/polypropylene, and carbon/epoxy adherends bonded with an acrylic-based adhesive. The fracture behaviors of the specimens are also discussed.

\section{Experimental procedures}

\section{Materials}

An aluminum alloy (5052-H34, average thickness $=3.0 \mathrm{~mm}$ ), a GF/PP matrix composite (Tepex dynalite 104-RG600(6)/47 \%, average thickness $=3.0 \mathrm{~mm}$, produced by Bond Laminates, Germany), and a CF/EP matrix composite (F6343B-05P $(0 / 90)_{14}$, average thickness $=3.3 \mathrm{~mm}$, produced by Toray Industries Inc., Japan) were used for the adherends. A two-part acrylic-based adhesive $\left(3 \mathrm{M}^{\mathrm{TM}}\right.$ Scotch-Weld ${ }^{\mathrm{TM}}$ Structural Plastic Adhesive DP8005, Japan) was used to bond the adherends. The advantages of this adhesive include its ability to bond adherends and polyolefins and its good resistance to water, humidity, and chemicals; moreover, it does not require pretreatment of the adherends and is a solvent-free adhesive system.

\section{Specimen preparation}

The shape and dimensions of the DCB specimen are shown in Fig. 1, based on ASTM D5528 [19]. A sandblast treatment was applied to the surfaces of the adherends, after which they were cleaned with acetone. A high-performance fluoropolymer-release film (WL5200, 0.001 in $\times 60$ in $\times 600 \mathrm{ft}$, produced by Airtech International Inc., USA) with

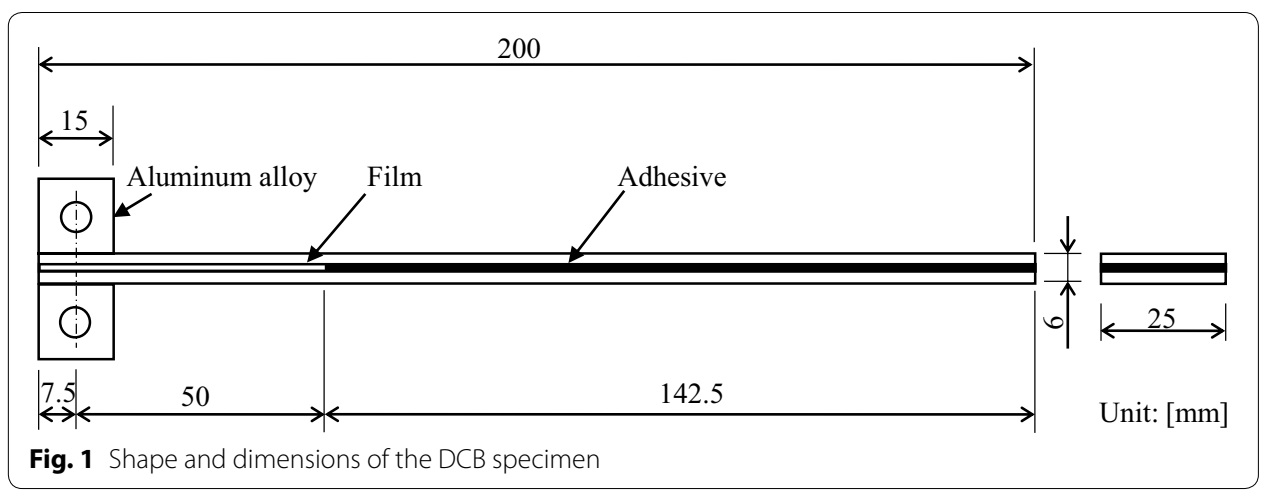


thickness of $25 \mu \mathrm{m}$ was used to create an initial crack. The DCB specimens were manufactured using a compression forming machine (high-pressure jack J-15, produced by the AS ONE Corporation, Japan) at room temperature for $20 \mathrm{~h}$. The set pressure was $5 \mathrm{MPa}$. The bond-line thickness was measured using a micrometer $(0.001 \mathrm{~mm}, \mathrm{MDC}$ $25 \mathrm{MJ}$, produced by the Mitutoyo Corporation, Japan). The differences between the total and adherend thicknesses of each specimen were measured at eight different positions between 70 and $160 \mathrm{~mm}$. Table 1 lists the measured values of the bond-line thicknesses of the DCB specimens. It has been reported that the critical value of the strain energy release rate is approximately constant between bond-line thicknesses of 0.102 and $0.254 \mathrm{~mm}[20]$.

An edge surface of the specimen was coated with white spray to highlight the crack tip. Perpendicular lines were drawn at $10 \mathrm{~mm}$ intervals on the edge of the DCB specimens.

\section{DCB tests}

The DCB tests were conducted based on ASTM D3433 [21] using a tensile test machine (Compact Table-Top Universal/Tensile Tester, EZ-S, produced by the Shimadzu Corporation, Japan) at a crosshead speed of $0.5 \mathrm{~mm} / \mathrm{min}$. The crack length was measured through a microscope (VH-ZST Swing-head Zoom Lens, VHX-5000 Digital Microscope, produced by the Keyence Corporation, Japan). To introduce an artificial crack, the DCB specimens were loaded until the crack length reached approximately $70 \mathrm{~mm}$, at which point the load was removed. This initial load-displacement curve was not used to measure the crack extension resistance. The numbers of specimens that were tested were three, four, and three for aluminum alloy, GF/PP, and CF/EP, respectively.

Figure 2 shows a schematic representation of the DCB test method. A DCB specimen was loaded until its crack grew to a length of approximately $10 \mathrm{~mm}$ (points A-B). The load applied to the specimen was linearly proportional to the displacement and the crack did not grow during this period. The crack began to propagate gradually when inelastic load-displacement behavior was observed (points B-C). After the load reached its maximum value (point $C$ ), it decreased gradually with increasing displacement until the crack had propagated approximately $10 \mathrm{~mm}$ (points $\mathrm{C}-\mathrm{D}$ ). The test was paused for 5 min to rest the crack propagation (points D-E), and then, the crack length was measured (point E). The specimen was unloaded to $5 \mathrm{~N}$ and then re-loaded (points E-F-E). A series of such DCB tests were carried out until the crack length reached approximately $160 \mathrm{~mm}$.

\section{Macroscopic and microscopic methods of fracture-surface observation}

A digital camera (IXY Digital 70, produced by Canon Inc., Japan) was used for macroscopic analysis of the entire area of each fracture surface. A microscope (see "DCB tests"

Table 1 Bond-line thicknesses measured on the DCB specimens

\begin{tabular}{lll}
\hline Specimens & Average $(\mathbf{m m})$ & Standard deviation $(\mathrm{SD})(\mathbf{m m})$ \\
\hline Aluminum alloy & 0.196 & 0.036 \\
GF/PP & 0.159 & 0.047 \\
CF/EP & 0.112 & 0.036 \\
\hline
\end{tabular}




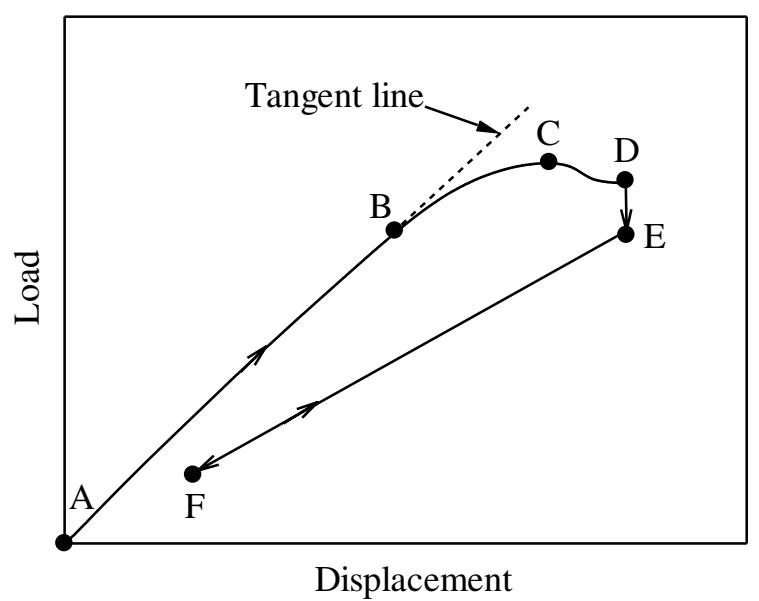

Fig. 2 Schematic representation of the DCB test method

section) was used as a means of microscopic analysis of the fracture surfaces (enlargement scale: $20 \times$ to $1000 \times$ ).

\section{Results and discussion}

\section{Load-displacement curves and maximum load versus crack length}

Figure 3 shows typical load-displacement $(P-\delta)$ curves for the DCB tests. The GF/PP specimens showed the largest displacements in comparison with the aluminum alloy and CF/EP ones. The experimentally measured maximum load was observed to decrease for all specimens in the displacement range of 15-100 $\mathrm{mm}$.

\section{Fracture toughness}

Irwin and Kies investigated the crack extension resistance (energy release rate) [22], which can be expressed as

$$
G_{I}=\frac{P^{2}}{2 b} \frac{d C}{d a}
$$

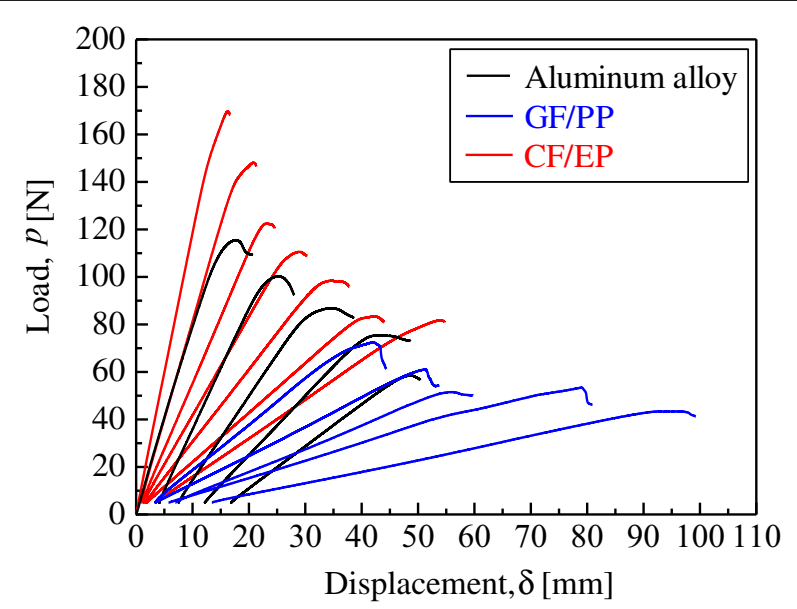

Fig. 3 Typical load-displacement curves for the DCB tests. The black, blue, and red solid lines were obtained from the aluminum alloy, GF/PP, and CF/EP specimens, respectively 
where $b$ is the specimen width and $a$ is the crack length. The fracture toughness $\left(G_{I C}\right)$ is defined as the maximum crack extension resistance $\left(G_{m}\right)$ [23]. The term $C$ is the compliance of the specimen, expressed as

$$
C=\frac{\delta}{P}
$$

The compliance is measured by an appropriate polynomial function,

$$
C=A_{1} a^{3}+A_{2} a^{2}+A_{3} a,
$$

where $A_{1}, A_{2}$, and $A_{3}$ are experimentally determined constants of the specimen.The compliance can also be measured using classical beam theory. In a double cantilever beam, the compliance [24] can be expressed as

$$
C_{d c b}=\frac{2}{3 E I} a^{3}
$$

where $E$ is the modulus of elasticity and $I$ is the moment of inertia of the cross section, given by

$$
I=\frac{b h^{3}}{12}
$$

where $h$ is the thickness. The moduli of elasticity for the aluminum alloy, GF/PP, and CF/ EP specimens were taken as 70, 20, and $50 \mathrm{GPa}$, respectively.

Experimental results for the dependence of the compliance on the crack length are plotted in Fig. 4. It was observed that the GF/PP specimens had the highest dependence, whereas the aluminum alloy ones had the lowest. The theoretical constants for the aluminum alloy, GF/PP, and CF/EP specimens were 1.591E-7, 6.902E-7, and 2.250E-7, respectively. The values of these constants are comparable with the experimental values of $A_{1}$.

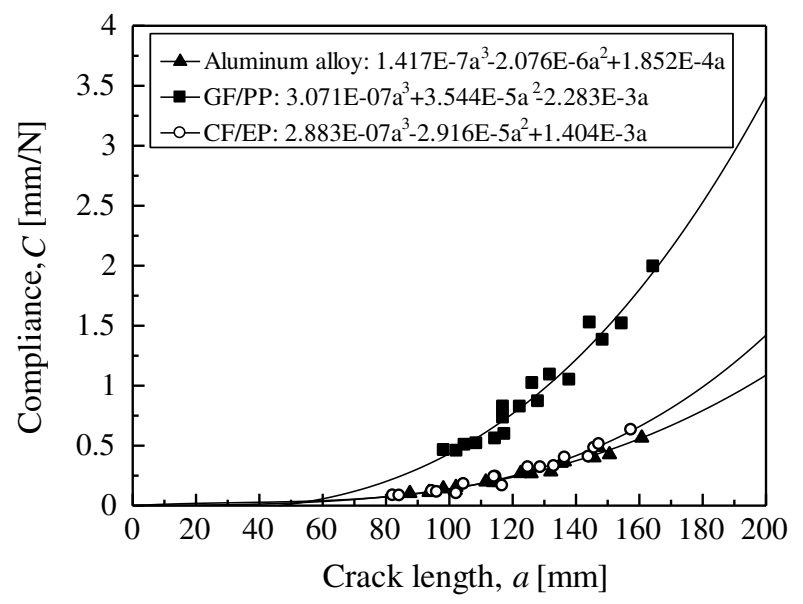

Fig. 4 Relationship between compliance and crack length. Closed black triangles, closed black rectangles, and open black circles were obtained experimentally from the aluminum alloy, GF/PP, and CF/EP specimens, respectively 
Figure 5 shows the typical ' $R$-curve' (i.e., the curve of crack extension resistance versus crack length) behaviors for the aluminum alloy, GF/PP, and CF/EP specimens. The difference $G_{m}-G_{i}$ indicates the difference between the maximum and initiation fracture toughness, while $a_{i}, a_{m}$, and $a_{r}$ represent the crack lengths at initiation, maximum, and rest-state fracture toughness, respectively. Aluminum alloy showed a relatively long steady-state crack propagation length. On the other hand, GF/PP and CF/EP specimens were observed to have not only short steady-state crack propagation lengths but also sharp decreases after their maximum values. The $R$-curve results for the DCB specimens are summarized in Table 2. The rest-state fracture toughness of each specimen was approximately the same as its initiation fracture toughness. The relatively low values of $G_{m}-G_{i}$ for aluminum alloy, as well as its relatively long crack propagation lengths $\left(a_{m}-a_{i}\right)$, support a larger inelastic deformation in the $R$-curve in comparison with the GF/PP and CF/EP specimens. There was no great distinction between the total crack propagation lengths $\left(a_{r}-a_{i}\right)$ of the aluminum alloy, GF/PP, and CF/EP specimens.

Figure 6 shows the values of fracture toughness $G_{I C}\left(=G_{m}\right)$ for the DCB tests. The average values of $G_{I C}$ for the aluminum alloy, GF/PP, and CF/EP specimens were 1071, 1438,

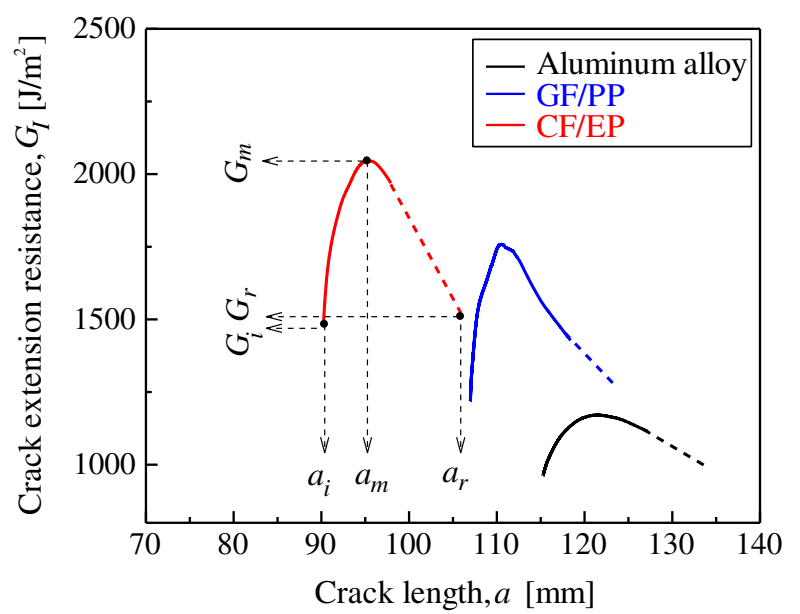

Fig. 5 Typical $R$-curves (crack extension resistance versus crack length). Black, blue, and red solid lines were obtained from the aluminum alloy, GF/PP, and CF/EP specimens, respectively

Table 2 Results of average initiation, rest state, and $G_{m}-G_{i}$ fracture toughness and crack propagation length for the DCB tests

\begin{tabular}{|c|c|c|c|c|c|c|c|}
\hline \multirow[t]{2}{*}{ Specimens } & \multirow{2}{*}{$\begin{array}{l}\begin{array}{l}\text { Fracture } \\
\text { toughness } \\
\left(\mathrm{Jm}^{-2}\right)\end{array} \\
G_{\max }=G_{I C}\end{array}$} & \multirow{2}{*}{$\begin{array}{l}\text { Initiation frac- } \\
\text { ture tough- } \\
\text { ness }\left(\mathrm{Jm}^{-2}\right) \\
G_{i}\end{array}$} & \multirow{2}{*}{$\begin{array}{l}\text { Rest-state } \\
\text { fracture } \\
\text { toughness } \\
\left(\mathrm{Jm}^{-2}\right) \\
G_{r}\end{array}$} & \multirow{2}{*}{$\begin{array}{l}\text { Difference } \\
\text { between maxi- } \\
\text { mum and ini- } \\
\text { tiation fracture } \\
\text { toughness } \\
\left(\mathrm{Jm}^{-2}\right) \\
G_{m}-G_{i}\end{array}$} & \multicolumn{3}{|c|}{$\begin{array}{l}\text { Crack propagation length } \\
(\mathrm{mm})\end{array}$} \\
\hline & & & & & $a_{m}-a_{i}$ & $a_{r}-a_{m}$ & $a_{r}-a_{i}$ \\
\hline $\begin{array}{l}\text { Aluminum } \\
\text { alloy }\end{array}$ & $1071(195.4)$ & $826.4(144.9)$ & $843.3(120.2)$ & $244.3(95.9)$ & $7.1(2.9)$ & $3.7(2.5)$ & $10.7(2.4)$ \\
\hline GF/PP & $1438(271.6)$ & $1185(270.2)$ & 1059 (179.1) & $253(181.2)$ & $3.1(2.3)$ & $9.1(4.5)$ & $12.2(4.2)$ \\
\hline CF/EP & $1652(225.2)$ & $1344(203.5)$ & 1308 (197.3) & 307 (149.7) & $4.0(0.8)$ & $7.5(5.4)$ & $11.5(5.6)$ \\
\hline
\end{tabular}

The relatively high standard deviation (SD) value for the crack propagation length of the GF/PP specimens was attributed to adherend failure involving weak bonding between the glass fibers and PP. Glass fibers present at various depths from the surface caused a variation in the crack propagation length $\left(a_{m}-a_{i}\right)$ because a crack will stop propagating when it reaches such obstacles 


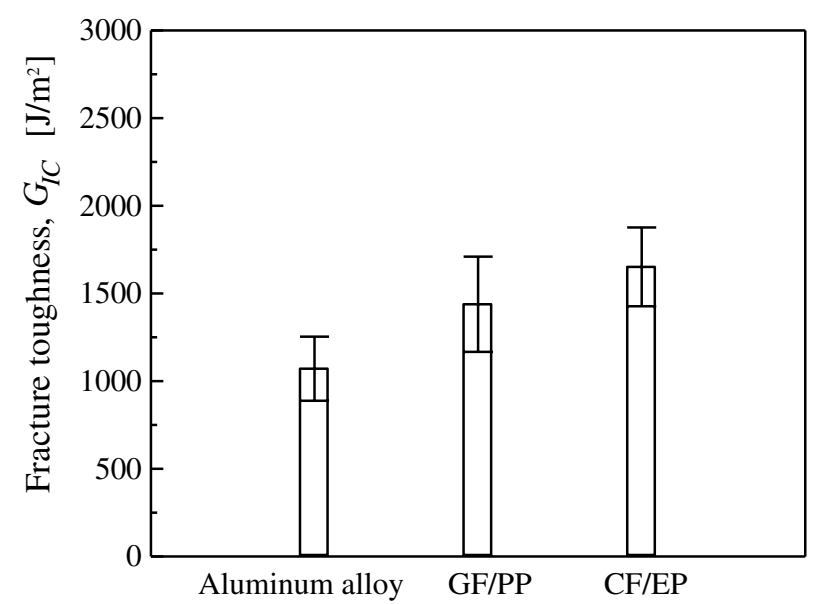

Fig. 6 Fracture toughness of DCB tests. Error bars indicate standard deviation

and $1652 \mathrm{Jm}^{-2}$, respectively. The SD values for the aluminum alloy, GF/PP, and CF/EP specimens were $195.4,271.6$, and $225.2 \mathrm{Jm}^{-2}$, respectively.

\section{Fracture surface observation}

Figure $7 \mathrm{a}-\mathrm{c}$ show representative fracture surfaces of the aluminum alloy specimen. The images in Fig. 7a, b are enlarged views taken by the microscope. The image in Fig. 7c was taken by a digital camera. A relatively large amount of interfacial failure was observed between the aluminum alloy and the adhesive, as shown in Fig. 7a, c. In addition, partial cohesive failures also occurred, as shown in Fig. 7b. Schematic representations of the fracture behavior are given in Fig. $7 \mathrm{~d}$. The crack propagated either to the interface between the aluminum alloy and the adhesive or into the adhesive. The experiments carried out by Del Real et al. showed a cohesive failure of aluminum alloy specimens when a $\gamma$-MPS treatment was applied [18]. It is important to apply surface treatments to the aluminum alloy in order to yield a cohesive failure. According to our experimental results using CF/EP specimens, a possible candidate is a primer (e.g., epoxy-like) that has good adhesion properties for both aluminum alloy and acrylic adhesive.

Representative fracture surfaces for the GF/PP specimen are shown in Fig. 8a-c. The entire fracture surfaces of this specimen exhibited a plain-weave pattern, as shown in Fig. 8c. Fiber pull-out and silky glass fibers were clearly observed, as shown in Fig. 8a, b. Note that fractures of the GF/PP specimens occurred mainly between glass fibers and PP. This is because the adhesions between the glass fibers and PP are weaker than the bonding between the adhesive and PP. These fracture surfaces resemble a plain-weave glass/toughened vinyl ester laminate [25]. Observation reveals that the crack propagated to the adherend interface between the glass fibers and PP, as illustrated in Fig. 8d.

Figure $9 \mathrm{a}-\mathrm{c}$ show the fracture surfaces for the CF/EP specimen. Adhesive deformation was observed on the fracture surfaces of the entire area, as shown in Fig. 9c. Fiber bridging and fiber pull-out were not observed, as shown in Fig. 9a, b. Fractures of the CF/ EP specimens were cohesive failures because the fiber/epoxy and epoxy/adhesive were bonded strongly, as illustrated in Fig. 9d. 


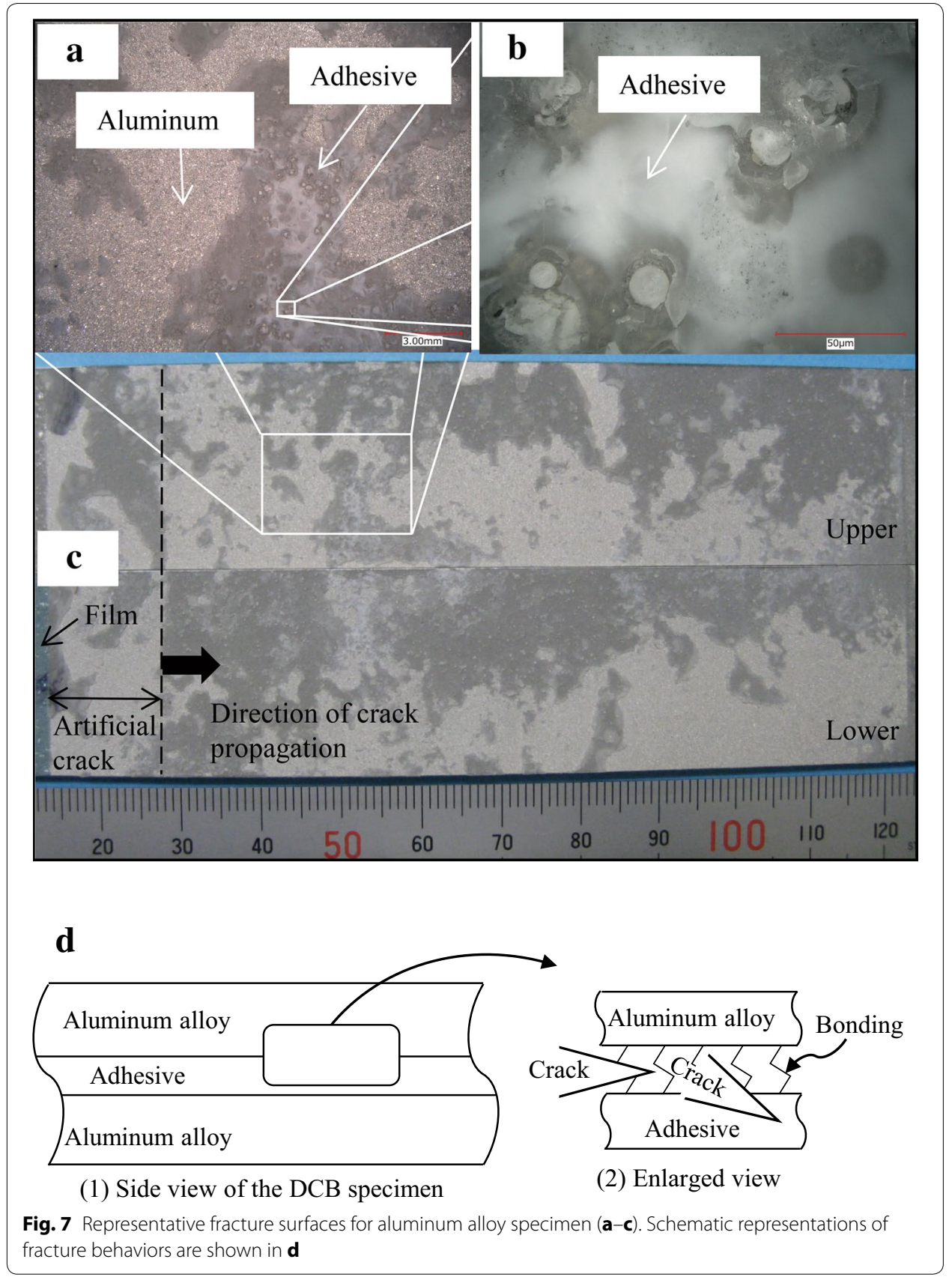

The aluminum alloy specimens had the lowest fracture toughness because of a lack of bonding between the aluminum alloy and the adhesive. The highest fracture toughness was obtained from the CF/EP specimens. This is because the constituent materials (i.e., carbon fiber, epoxy, and adhesive) were bonded together well, as compared to the GF/PP specimens in which poorer bonding was observed between the glass fibers and PP. The results of the DCB tests under Mode I static loading showed a correlation between the fracture toughness and fracture morphology of the specimens, i.e., the values of fracture toughness (fracture morphology) can be ranked as aluminum alloy (interfacial) <GF/PP (adherends) $<\mathrm{CF} / \mathrm{EP}$ (cohesive). 


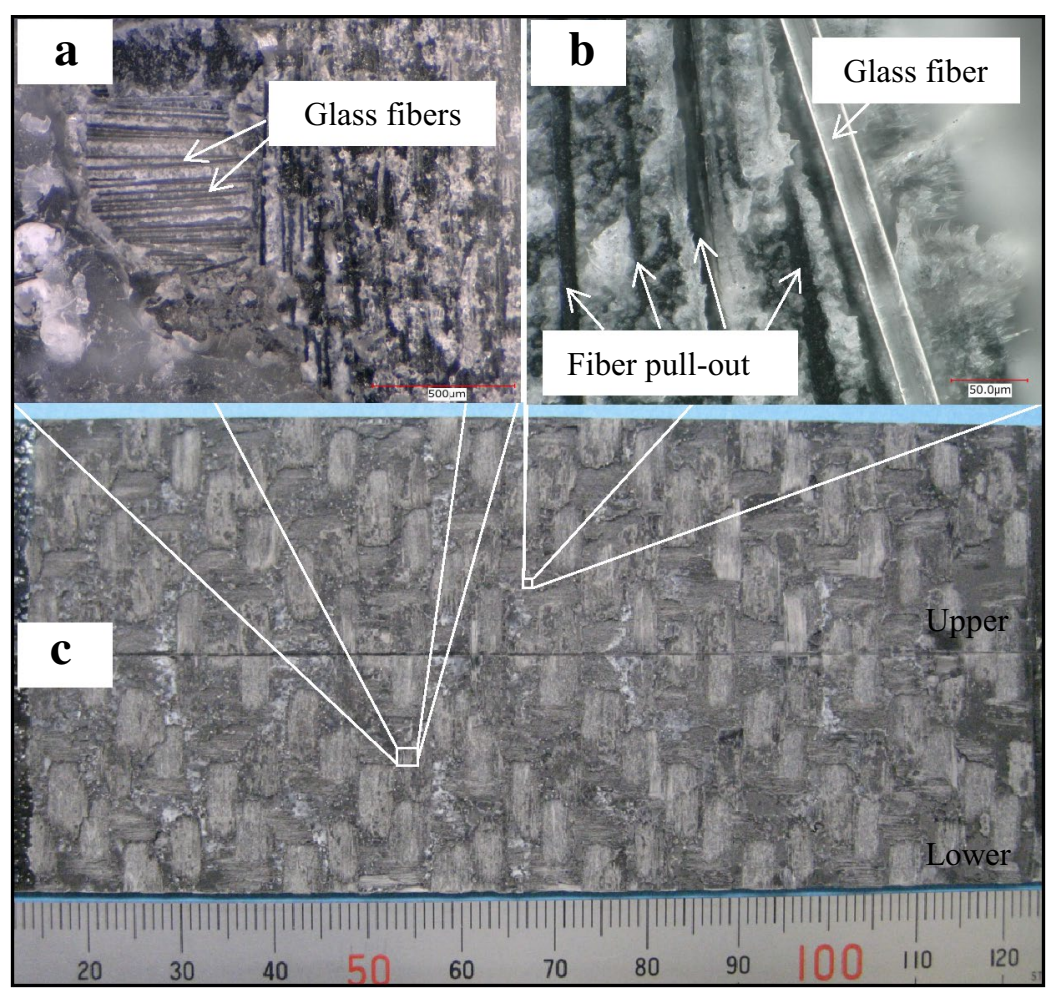

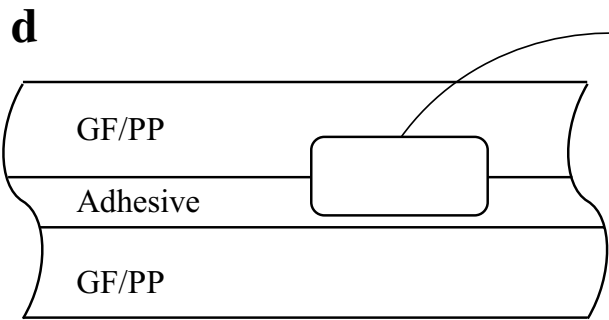

(1) Side view of the DCB specimen

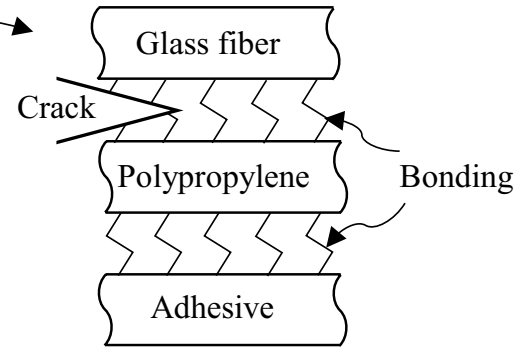

(2) Enlarged view

Fig. 8 Representative fracture surfaces for GF/PP specimen (a-c). Schematic representations of fracture behaviors are shown in $\mathbf{d}$

\section{Conclusions}

DCB tests were conducted to measure fracture toughness in different types of adherends bonded with a two-part acrylic-based adhesive, i.e., aluminum alloy, GF/PP, and CF/EP. The values of fracture toughness for the aluminum alloy, GF/PP, and CF/EP specimens were 1071,1438 , and $1652 \mathrm{Jm}^{-2}$, respectively. It was confirmed by investigating the fracture surfaces that the fractures of the aluminum alloy specimens occurred mainly between the aluminum alloy and the adhesive. Relatively poor bonding between the GFs and PP caused delamination of the adherends in the GF/PP specimens. The fracture surfaces of the CF/EP specimens were cohesive failures. It can be concluded that the fracture toughness of the specimens is closely related to the fracture morphology of 

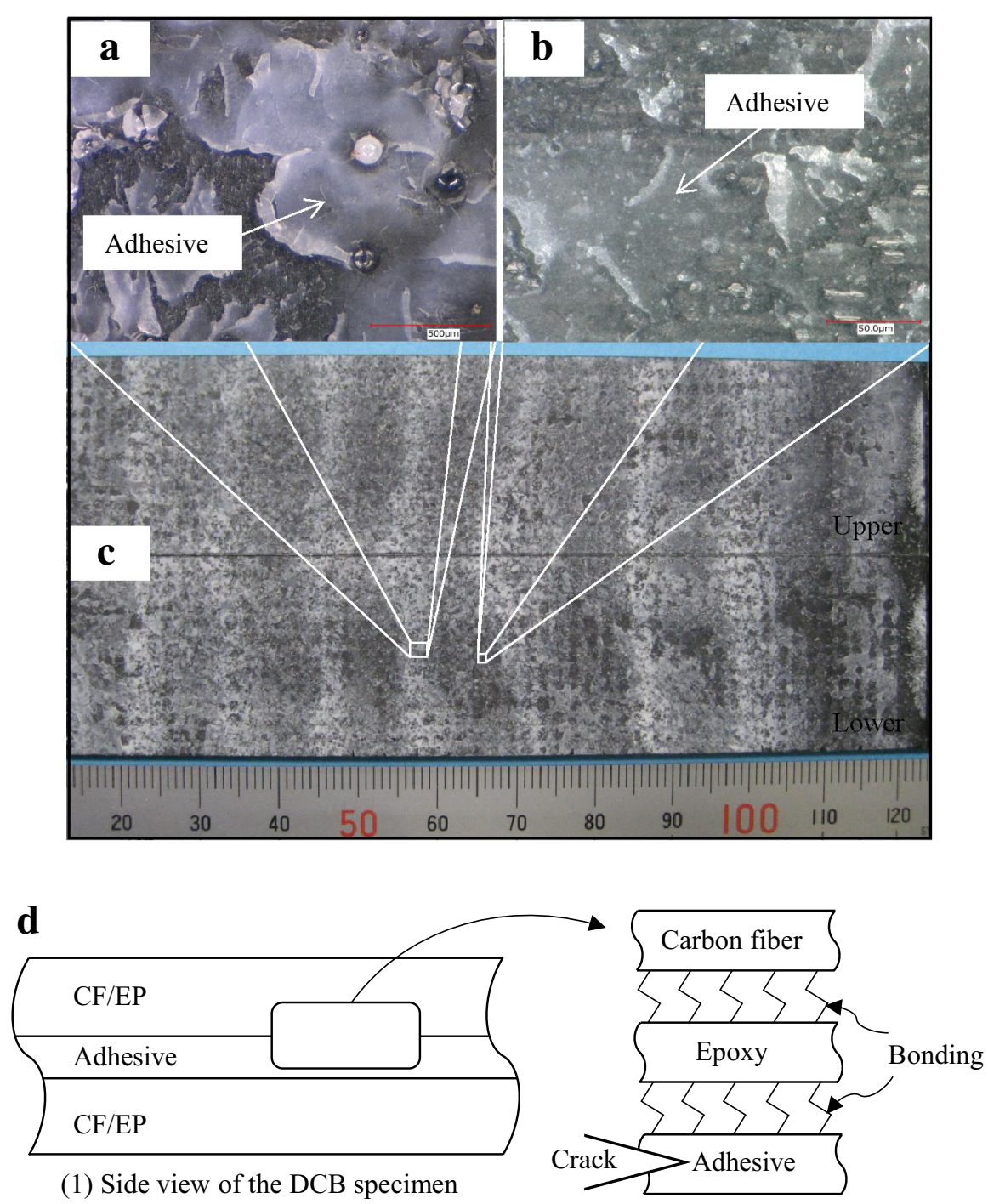

(2) Enlarged view

Fig. 9 Fracture surfaces for CF/EP specimen $(\mathbf{a}-\mathbf{c})$. Schematic representations of fracture behaviors are shown in $\mathbf{d}$

the fracture surfaces. Future work includes an investigation of proper surface treatments and modification of the adhesive to improve the fracture toughness.

\section{Authors' contributions}

$\mathrm{HK}, \mathrm{KN}$, and $\mathrm{HO}$ made the specimens. KN prepared the experimental setup. $\mathrm{HK}$ conducted the experiments. KN and $\mathrm{HO}$ supported for HK to write the paper. All authors read and approved the final manuscript.

\section{Acknowledgements}

This paper is based on results obtained from a future pioneering project commissioned by the New Energy and Industrial Technology Development Organization (NEDO).

\section{Competing interests}

The authors declare that they have no competing interests.

Received: 9 May 2016 Accepted: 22 June 2016

Published online: 29 June 2016 
References

1. Kozuh Z, Jralj S, Cvirn Z. Advantages and application possibilities of adhesive bonding. Promet-Traffic-Traffico. 1997;9(1-2):33-40.

2. Adderley CS. Adhesive bonding. Mater Des. 1988;9(5):287-93.

3. Fernlund G, Papini M, McCammond D, Spelt JK. Fracture load predictions for adhesive joints. Compo Sci Tech. 1994;51:587-600.

4. da Lucassilva FM, Rodrigues TNSS, Figueiredo MAV, de Moura MFSF, Chousal JAG. Effect of adhesive type and thickness on the lap shear strength. J Adhes. 2006;82:1091-115.

5. Campilho RDSG, de Moura MFSF, Domingues JJMS. Modelling single and double-lap repairs on composite materials. Compos Sci Tech. 2005;65:1948-58.

6. da Lucassilva FM, Ramos JE, Figueiredo MV, Strohaecker TR. Influence of the adhesive, the adherend and the overlap on the single lap shear strength. J Adhes Interface. 2006;7(4):1-9.

7. Lehman GM, Hawley AV. Investigation of joints in advanced fibrous composites for aircraft structures, Technical Report No. 1979. AFFDL-TR-69-43.

8. Kusaka Takayuki, Hojo Masaki, Mai Yiu-Wing, Kurokawa Tomoaki, Nojima Taketoshi, Ochiai Shojiro. Rate dependence of mode I fracture behavior in carbon-fiber/epoxy composite laminates. Compo Sci Tech. 1998;58:591-602.

9. Pereira $\mathrm{AB}$, de Morais $\mathrm{A}$. Mode I interlaminar fracture of carbon/epoxy multidirectional laminates. Compo Sci Tech. 2004:64:2261-70.

10. Ungsuwarungsri T, Knauss WG. The role of damage-softened material behavior in the fracture of composites and adhesives. Int J of Fract. 1987;35:221-41.

11. Yoshihara Hiroshi. Simple estimation of critical stress intensity factors of wood by tests with double cantilever beam and three-point end-notched flexure. Holzforschung. 2007:61:182-9.

12. Sørensen Bent F. Cohesive law and notch sensitivity of adhesive joints. Acta Mater. 2002;50:1053-61.

13. Khayer Dastjerdi A, Tan E, Barthelat F. Direct measurement of the cohesive law of adhesives using a rigid double cantilever beam technique. Exp Mech. 2013;53(9):1763-72.

14. Gagliano Jerone M, Frazier Charles E. Improvements in the fracture cleavage testing of adhesively-bonded wood. Wood Fiber Sci. 2001;33(3):377-85.

15. Mahaphasukwat Siripong, Shimamoto Kazumasa, Shota Hayashida Yu, Sekiguchi Chiaki Sato. Mode I critical fracture energy of adhesively bonded joints between glass fiber reinforced thermoplasitcs. Appl Adhes Sci. 2015;3(4):1-13.

16. del Real-Romero JC, Ballesteros Y, Chamochín R, Abenojar J, Molisani L. Influence of surface preparation on the fracture behavior of acrylic adhesive/CFRP composite joints. J Adhes. 2011;87:366-81.

17. Chamochín R, Cano M, Abenojar J, Pantoja M, Ballesteros Y, del Real-Romero JC. The effect of surface treatment on the behavior of toughened acrylic adhesive/GRP(epoxy) composite joints. J Adhes Sci Technol. 2010:24:1801-18.

18. del Real-Romero JC, Cano M, Abenojar J, Pantoja M, Martínez MA. Influence of silanisation parameters with $\gamma$-m ethacryloxypropyltrimethoxysilane on durability of aluminium/acrylic adhesive joints. J Adhes Sci Technol. 2008;22:1461-75

19. ASTM D 5528-01. Standard test method for Mode I interlaminar fracture toughness of unidirectional fiber-reinforced polymer matrix composites, in annual book of ASTM standards, 200515.03.

20. Mall S, Ramamurthy G. Effect of bond thickness on fracture and fatigue strength of adhesively bonded composite joints. Int J Adhes Adhes. 1989;9(1):33-7.

21. ASTM D3433-99. Standard test method for fracture strength in cleavage of adhesives in bonded metal joints, in annual book of ASTM standards, 2005. 15.06

22. Irwin GR, Kies JA. Critical energy rate analysis of fracture. Welding J. 1955;33:193-8.

23. Beer FP, Johnston ER, Dewolf JT, Mazurek DF. Mechanics of materials. 6th ed. New York: MaGraw-Hill; 2012.

24. Madhukar Madhu S, Drzal Lawrence T. Fiber-matrix adhesion and its effect on composite mechanical properties: IV. Mode I and Mode II Fracture Toughness of Graphite/Epoxy Composites. J Compos Mater. 1992;26(7):936-68.

25. Panuwat Suppakul and Sri Bandyopadhyay. The effect of weave pattern on the mode-l interlaminar fracture energy of E-glass/vinyl ester composites. Compos Sci Tech. 2002;62:709-17.

\section{Submit your manuscript to a SpringerOpen ${ }^{\circ}$ journal and benefit from:}

- Convenient online submission

- Rigorous peer review

- Immediate publication on acceptance

- Open access: articles freely available online

- High visibility within the field

- Retaining the copyright to your article

Submit your next manuscript at $>$ springeropen.com 